\title{
Rationing access to total hip and total knee replacement in the Islamic Republic of Iran to reduce unnecessary costs: policy brief
}

Mohammad Soleimani, ${ }^{1}$ Shoresh Barkhordari, ${ }^{1}$ Farhad Mardani, ${ }^{2}$ Nasrin Shaarbafchizadeh ${ }^{3}$ and Fatemeh Naghavi-Al-Hosseini ${ }^{4}$

${ }^{1}$ Faculty of Medical Science, Isfahan University of Medical Sciences, Isfahan, Islamic Republic of Iran. ${ }^{2}$ Faculty of Dental Science, Isfahan University of Medical Sciences, Isfahan, Islamic Republic of Iran. ${ }^{3}$ Health Management and Economics Research Center, Faculty of Management and Medical Information, Isfahan University of Medical Sciences, Isfahan, Islamic Republic of Iran. ${ }^{4}$ Faculty of Pharmaceutical Science, Isfahan University of Medical Sciences, Isfahan, Islamic Republic of Iran. (Correspondence to: Fatemeh Naghavi-Al-Hosseini: f.naghavi.94@gmail.com).

\begin{abstract}
Rationing health services is an inseparable part of the health system of any country in order to achieve universal health coverage. Elective surgery for total hip and total knee replacement places a high financial burden on health systems. Such surgery should be done in a way to ensure that the people who most need it receive the service. Models for rationing total hip and knee replacement surgery were reviewed to suggest the best policy for rationing such surgery in the Islamic Republic of Iran. We propose a system with three main tools: clinical guidelines, gate keepers and waiting lists, with shared decision-making as an auxiliary tool. Patients should be scored at the primary health care level based on clinical and radiographic examination, alternative treatments (conservative treatments) and risk factors, with a set threshold for referral. Patients whose scores are above the threshold should be referred to secondary health care. These patients should be assessed again by specialists based on age, bone condition, surgery risk and other alternative treatments. Patients whose scores are above the threshold should be put on the waiting list for surgery.
\end{abstract}

Keywords: arthroplasty, replacement, knee, hip, elective surgery, health services, policy, Iran

Citation: Soleimani M; Barkhordari S; Mardani F; Shaarbafchizadeh N; Naghavi-Al-Hosseini F. Rationing access to total hip and total knee replacement in the Islamic Republic of Iran to reduce unnecessary costs: policy brief. East Mediterr Health J. 2020;26(11):1396-1402. https://doi.org/10.26719/ emhj.20.109

Received: 04/04/19; accepted: 17/10/19

Copyright $@$ World Health Organization (WHO) 2020. Open Access. Some rights reserved. This work is available under the CC BY-NC-SA 3.0 IGO license (https://creativecommons.org/licenses/by-nc-sa/3.o/igo)

\section{Introduction}

Health costs have increased faster than global economic growth over the past 15 years (1), which is an important issue for health systems. Financial resources allocated to health services are generally inadequate, especially in developing countries. As a result these services have only a small effect on public health and tend to benefit rich people more (2). One of the solutions to this problem that the World Health Organization has promoted as a prerequisite for achieving universal health coverage is rationing (3). Rationing has been referred to as not providing services, which are considered to have benefits, to some people (4).

Surgical operations for the total hip replacement and total knee replacement impose a large financial burden on the health system. Although these surgeries are mostly considered as the last-resort solution for treatment, studies show that nonsurgical treatments, such as physical therapy, can be more effective in hip and knee osteoarthritis compared with having no treatment (5). The increased average age of the world population and the higher prevalence of obesity and osteoarthritis together with increased health costs have led to concerns about the health system's capacity to provide these procedures and consequently the need for rationing to ensure that people in most need have access to them $(1,6-8)$.

\section{Main problem}

The fast-growing increase in osteoarthritis in low- and middle-income countries is similar to the increase in high-income countries. Some studies have reported a faster increase in some low- and middle-income countries, which could be associated with low levels of education in these countries (9-11). According to a study in the Islamic Republic of Iran, the prevalence of osteoarthritis was $16.6 \%$ in urban areas and $20.5 \%$ in rural areas (12).

Arthritis is the second leading disease causing longterm disability in individuals with the disease globally. The years spent with disability from arthritis increased by about 75\% between 1990 and 2013 (13). In 2015, among 34 European and some Asian countries, on average 282 total hip replacements and total knee replacements were done per 100000 people (14). According to reports of one of the main social insurance organizations in the Islamic Republic of Iran, primary orthopaedic surgery has been an obligation of insurance organizations since 2000. There are fewer than 10 ooo knee surgeries a year in the country, but this figure is likely to reach to 30000 in the next 5 years. The cost of this operation was high before the 2014 health system reform plan in the Islamic Republic of Iran, but the operation is now covered by insurance at a percentage rate of charge or free of charge (15). However, because of weaknesses in the plan, especially an inadequate referral system, cost issues and 
ineffective negotiation with insurance companies, more reforms in health system policies are needed (16).

\section{Aim of the policy brief}

We aimed to develop a policy brief that helps the health system in the Islamic Republic of Iran to ration elective hip and knee joint replacement surgery in an equitable and clinically beneficial way.

\section{Methods}

We developed this policy brief through a literature review and group discussions among ourselves. We searched PubMed, Scopus, Web of Science, Embase, and Google Scholar up to 2019 using the keywords in English: "rationing", "hip replacement", "knee replacement" and "elective surgery". In addition, the Guideline of American College of Rheumatology on hip and knee osteoarthritis (17) and the clinical guidelines of the Iranian Orthopaedic Society were used to assess the use of guidelines.

\section{Policy options}

Different tools have been used in rationing. These tools include waiting lists, clinical guidelines and gate-keeper systems. Shared decision-making is an auxiliary tool that has been effective in cost reduction but it has not been used as a tool on its own. In most countries, these tools have been used together, but to facilitate our analysis, we evaluated the tools separately.

\section{Clinical guidelines}

Clinical guidelines are used in New Zealand and the United Kingdom of Great Britain and Northern Ireland at the micro-level where rationing is based on the views of physicians of indications and contraindications for a medical service (18). However, in developing countries, this method is used at a higher (meso-) level where insurance providers and hospitals determine the clinical guidelines. The main feature of the use of clinical guidelines is the use of evidenced-based medicine. However, there are many disagreements on the indications and contraindications for total knee replacement surgery (19).

In the studies we reviewed, rationing using clinical guidelines is not only considered an independent method of rationing but also an integral part of implementation of other rationing methods. For example, the American College of Rheumatology proposes conservative treatments such as water therapy and aerobic exercise for patients with osteoarthritis rather than surgery (17). The clinical criteria of age, bone status, surgical risk, preoperative procedures and motor limitations have been used to determine whether surgery is appropriate for patients with osteoarthritis or not (20).

In 2006, the United Kingdom established a threshold of body mass index less than $30 \mathrm{~kg} / \mathrm{m}^{2}$ for knee and hip surgeries. As a result, 8452 pelvic surgeries and 12929 knee surgeries were eliminated, with a significant cost reduction (21). Obese people were 1.3 times more likely to have postoperative complications from shoulder, hip and knee surgery than people with normal weight (22). Obesity has also been associated with an increase in admission time in the hospital for people undergoing joint surgery (23). However, such a threshold would seem to deprive many people who are highly in need of this surgery of receiving it (24). Usually, total knee replacement is not done in people younger than 50 years or older than 80 years (25). In younger people, this is because of the potential complications of the surgery, and in older people this is because of their muscular condition and lack of movement and exercise, which can reduce the effectiveness of these operations (26).

\section{Gate-keeper system}

In a gate-keeper system, people cannot access second-level services such as the hospital and specialist physician without referral by a general practitioner. This system has two main benefits: (i) cost control by reducing unnecessary interventions, and (ii) use of effective secondary services because physicians are better informed than patients about the quality of services provided by secondary providers (27).

A study showed that $97 \%$ of people with severe knee problems, who were receiving secondary services, had initially seen a general practitioner (28). Another study showed that only $67 \%$ of orthopaedic referrals by general practitioners were appropriate (29). For appropriate referral, we need a referral threshold based on a clinical guideline that is available to general practitioners, such systems have been used in different countries. A review study proposed that general practitioners should consider four factors in referral for joint surgery: (i) Do clinical and radiographic characteristics of the patient justify the referral?; (ii) Has the patient had appropriate conservative treatments?; (iii) Does the patient have risk factors that might adversely affect the outcome of surgery?; and (iv) Can these risk factors be modified? (20)

In a study in Switzerland in $2000,20 \%$ cost reduction was observed as a result of the gate-keeper system (30).

\section{Waiting lists}

Two methods have been used to include the people on a waiting list. In the queue-based model, people are included on the waiting list based on the time of their referral, regardless of disease severity. This method is a chancebased prioritization. The other model is a scoring model where an individual's position on the waiting list is based on specific scores for severity and need (6).

Different scoring systems are used in different countries to accommodate individuals on the waiting list for joint replacement surgery. The most commonly used systems are the Oxford hip and knee score, reduced Western Ontario McMaster osteoarthritis index (WOMAC) score, New Zealand Orthopaedic Association score, clinical priority assessment criteria, and the score of the multi-attribute arthritis prioritization tool (6,31-33).

According to the New Zealand Orthopaedic Association system, patients are scored from o to 100 . After referral, each patient is scored by a consultant and 
a nurse at the first visit with the specialist. Based on a defined threshold limit appropriate for conditions in the country, patients below the threshold are referred back to the general practitioner. Patients above the threshold limit are referred to the orthopaedic department and evaluated by a surgeon, who manages the waiting list. A study in New Zealand indicated that of 608 patients examined, $32 \%$ were referred back to the general practitioner based on this threshold, thus reducing the number of patients on the waiting list (33).

In England, the use of the Oxford hip and knee score for knee surgery resulted in a cost reduction of $£ 11.8$ million a year $(\varepsilon 1=$ US\$1.6041 in 2011, the date of the cited study) (31). The Oxford hip score questionnaire was translated into Farsi for use in the Islamic Republic of Iran for pre-operative total hip replacement patients (34). The adapted and validated Iranian version of the Oxford hip score questionnaire was found to be reliable and practicable for use with Iranian patients (34).

\section{Shared decision-making}

Clinical shared decision-making is not discussed as means of rationing, but can be considered an auxiliary tool for rationing. Shared decision-making can contribute to fair rationing along with other tools. Research has shown that patients are willing to share in the decision-making for their health care (6). In the United Kingdom, it was shown that individuals consider pain severity, inability to walk, costs and postoperative care some of the clinical criteria for joint replacement surgery (20) . Another study showed that $44-55 \%$ of people who required total knee replacement and total hip replacement were certainly or probably unwilling to have surgery (35). In another study, if individuals were consulted about their willingness to have surgery after the complications and conditions of the surgery were explained, a $36 \%$ cost reduction in joint replacement surgery was seen (36). Thus, prioritization of patients on the waiting list can be based on clinical criteria and the views of the patients themselves about the need for surgery (37).

\section{Policy recommendations}

Based on our evaluation of the various methods for rationing surgical care (clinical guidelines, waiting lists, gate-keeper systems, and shared decision-making), Table 1 lists the disadvantages, benefits, and policy options for each method.

\section{Clinical guidelines}

Clinical guidelines are the basis of the rationing method in many cases. Most clinical guidelines are based on evidence; however, clinical guidelines can also be based on consensus (38).

The policy implemented in the United Kingdom to establish a threshold linked to body mass index is a special type of rationing based on clinical guidelines. Although this policy had many critics, it did reduce costs and time to admission to hospital (16) . Furthermore, the age of people can determine candidates for surgery.
Clinical guidelines are necessary for rationing, and countries should develop guidelines relevant to their context. The Iranian Orthopaedic Association published a clinical guideline on joint replacement surgery in 2016 . However, this guideline has not yet been implemented, so no cost-effectiveness assessment could be done (39).

\section{Waiting list}

Although a scoring-based waiting list is preferred to a list based on the time entered on the list, both methods have reduced costs. It should be noted that more developed countries have moved from a queuing model to a scoring model.

\section{Gate-keeper system}

As shown in Figure 1, gate keepers are the first line of rationing. Since most people with serious joint problems go to general practitioners first and the referrals of general practitioners have been effective for accessing treatment (40), this rationing tool is recommended. In addition, an appropriate referral threshold can make the referrals more effective. Given the unsuccessful experience with an urban referral system in the Islamic Republic of Iran in 2005 , a system should be designed with a referral threshold based on clinical guidelines. This system should be piloted and the results evaluated.

\section{Proposed rationing system}

We propose a system summarized in Figure 1 with three main tools: clinical guidelines, gate keepers and waiting lists, with shared decision-making as an auxiliary tool. For patients to enter the rationing system for treatment through the gate keeper, they must be scored first by the primary health care units based on clinical and radiographic examination, alternative treatments (conservative treatments) and risk factors. Patient whose scores are below the threshold, should be referred by general practitioners to physiotherapists for conservative treatment such as hydrotherapy and exercise. Patients whose scores are above the threshold, should be referred to secondary health care units. At this stage, patients are assessed by specialists and are scored on age, bone condition, risk of surgery and other alternative treatments. Patients whose scores are below this threshold will be referred to physiotherapists again. Patients whose scores are above the threshold should be placed on a waiting list and prioritized according to age, sex, body mass index, occupation and history of total knee or hip replacement. As illustrated in Figure 1, decision-making should be actively shared with patients; they should be encouraged to share their ideas about treatment and other options that may be available.

\section{Implementation of recommendations}

In order to implement the recommendations in our policy brief at the mid-level in the Islamic Republic of Iran, the following process should be followed. First, establish a policy-makers' group consisting of heads of universities of medical sciences, heads of hospitals, representative of the orthopaedic association, insurance providers, trusted 


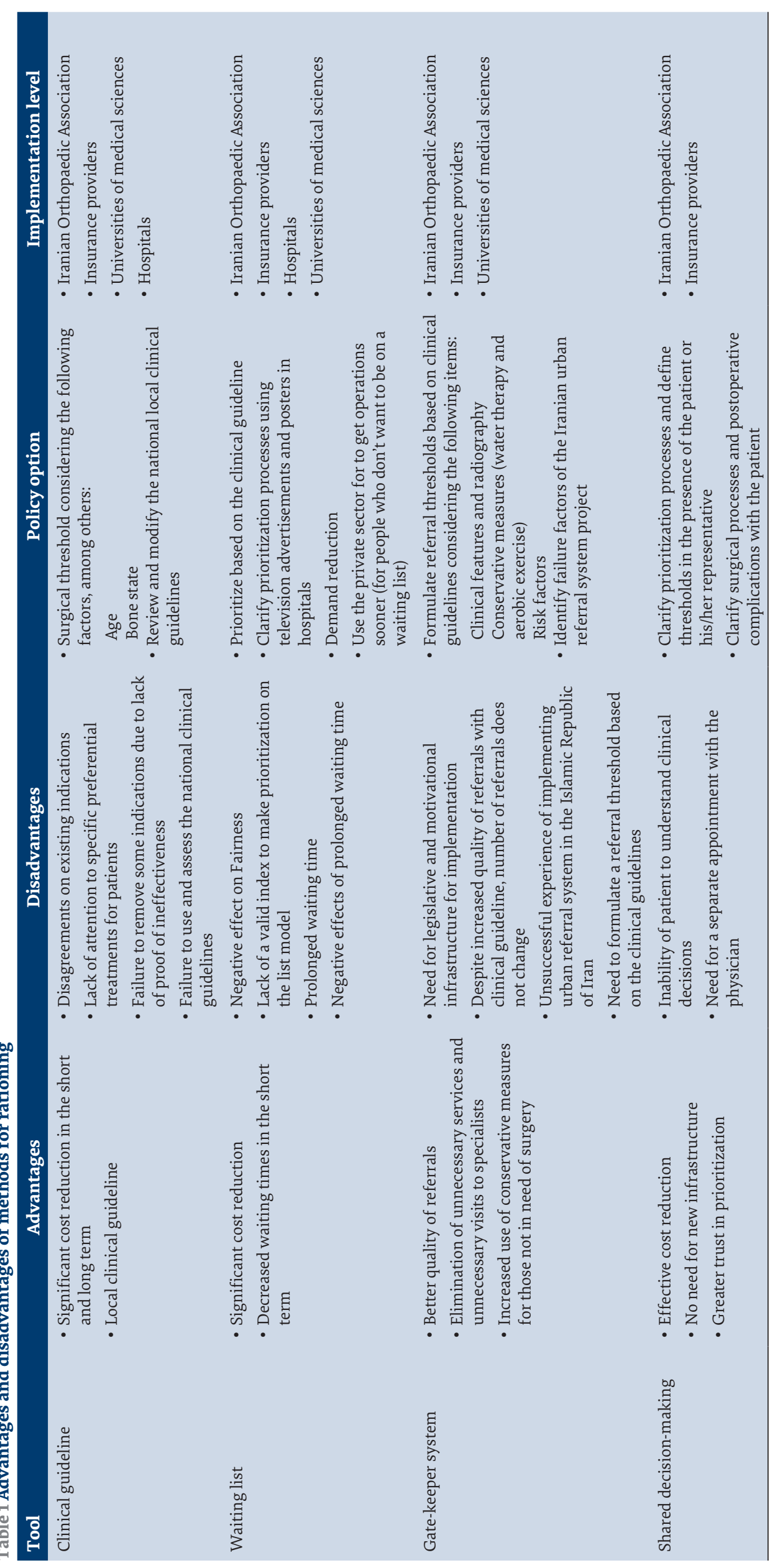




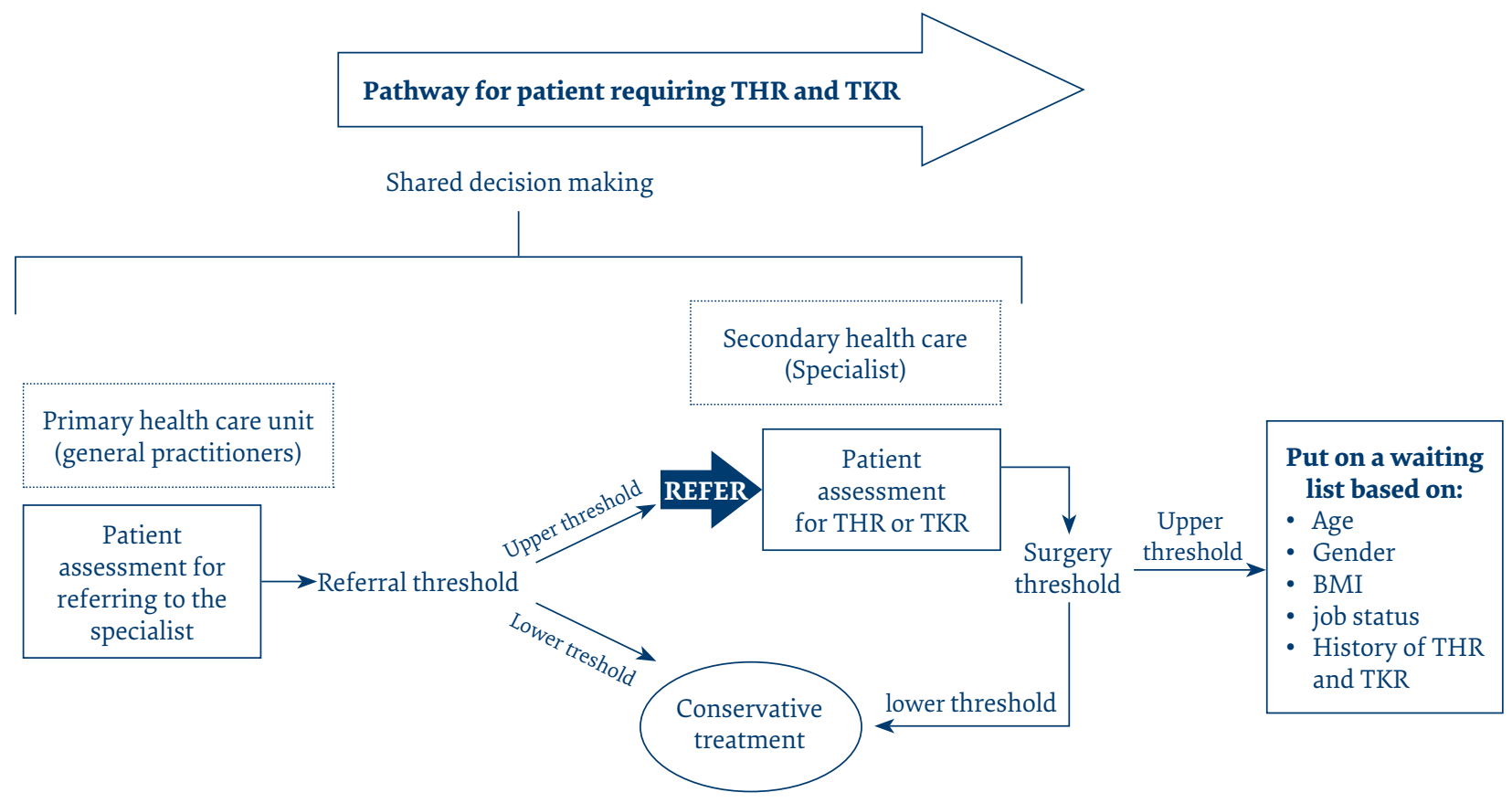

orthopaedic surgeons, representative of general practitioners and physiotherapists. Establish a research group, consisting of for example general practitioners, specialists and statisticians, to evaluate and validate the clinical guidelines developed in 2016 by the Iranian Orthopaedic Association. Second, modify the clinical guidelines based on the results. Third, establish thresholds for referral and surgery based on the clinical guidelines. Fourth, reach an agreement with insurance providers and patient representatives on the cost of treatment that insurance covers.

Funding: National Agency for Strategic Research in Medical Education, Tehran (grant no. 971935).

Competing interests: None declared.

\section{Limitation des interventions de prothèse totale de la hanche et du genou en République islamique d'Iran en vue de réduire les coûts inutiles : note d'orientation Résumé}

La limitation des services de santé est une composante indissociable du système de santé de tout pays dans l'objectif de parvenir à la couverture sanitaire universelle. La chirurgie programmée pour la prothèse totale de la hanche et du genou constitue une lourde charge financière pour les systèmes de santé. Cette chirurgie doit être effectuée de manière à ce que les personnes qui en ont le plus besoin en bénéficient. Les modèles de limitation de la chirurgie totale de la hanche et du genou ont été examinés afin de proposer la meilleure politique pour limiter ce type d'intervention en République islamique d'Iran. Nous proposons un système comportant trois outils principaux : les lignes directrices cliniques, les filtres et les listes d'attente, avec la prise de décision partagée comme outil auxiliaire. Les patients doivent être évalués au niveau des soins de santé primaires sur la base de l'examen clinique et radiographique, des traitements alternatifs (traitements conservateurs) et des facteurs de risque, avec un seuil défini pour l'orientation-recours. Les patients dont les scores sont supérieurs au seuil doivent être orientés vers les soins de santé secondaires. Ces patients doivent être réévalués par des spécialistes en fonction de leur âge, de leur condition osseuse, du risque chirurgical et d'autres traitements alternatifs. Les patients dont les scores sont supérieurs au seuil doivent être ensuite placés sur la liste d'attente des interventions chirurgicales. 


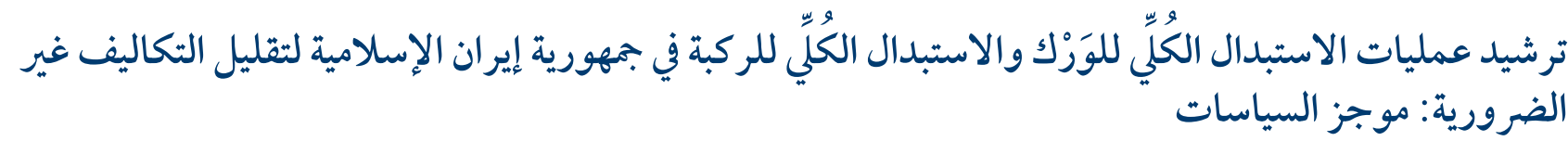

محمد سلياني، شورش برخوردارى، فرهاد مرداني، نسرين شعربافهى زاده، فاطمه نقوى الحسينى

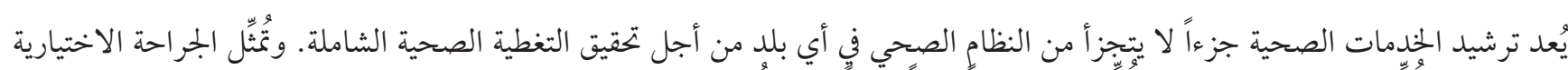

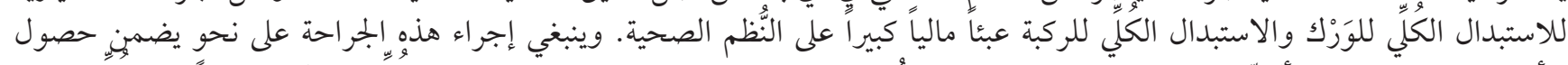

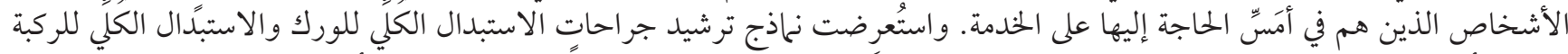

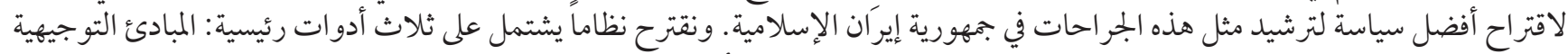

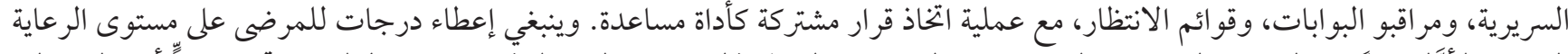

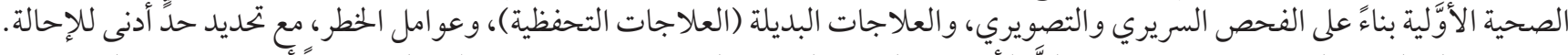

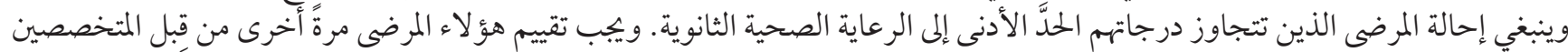

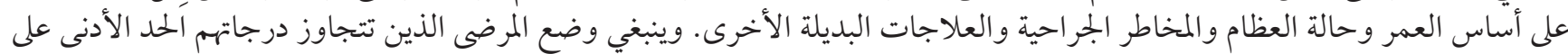

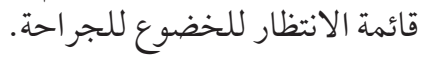

\section{References}

1. Global spending on health: a world in transition. Geneva: World Health Organization; 2019 (https://apps.who.int/iris/bitstream/ handle/10665/330357/WHO-HIS-HGF-HF-WorkingPaper-19.4-eng.pdf?ua=1, accessed 14 June 2020).

2. James C, Carrin G, Savedoff W, Hanvoravongchai P. Clarifying efficiency-equity trade-offs through explicit criteria, with a focus on developing countries. Health Care Anal. 2005;13(1):33-51. https://doi.org/10.1007/s10728-005-2568-2

3. The world health report: health systems financing: the path to universal coverage. Geneva: World Health Organization; 2010 (https://www.who.int/whr/2010/en/, accessed 14 June 2020).

4. Brock DW. Health care resource prioritization and rationing: why is it so difficult? Soc Res. 2007;74(1):125-48.

5. Smidt N, de Vet HC, Bouter LM, Dekker J. Effectiveness of exercise therapy: a best-evidence summary of systematic reviews. Aust J Physiother. 2005;51(2):71-85. https://doi.org/10.1016/s0004-9514(05)70036-2

6. Cipriano LE, Chesworth BM, Anderson CK, Zaric G. An evaluation of strategies to reduce waiting times for total joint replacement in Ontario. Med Care. 2008;46(11):1177-83. https://doi.org/10.1097/MLR.obo13e31817925e8

7. He W, Goodkind D, Kowal P. An aging world: 2015. Washington, DC: US Government Publishing Office; 2016 (US Census Bureau, International Population Reports, P95/16-1).

8. The world health report: obesity and overweight: World Health Organization. (2018). 2019.

9. Cross M, Smith E, Hoy D, Carmona L, Wolfe F, Vos T, et al. The global burden of rheumatoid arthritis: estimates from the global burden of disease 2010 study. Ann Rheum Dis. 2014;73(7):1316-22. https://doi.org/10.1136/annrheumdis-2013-204627

10. Zhang Y, Jordan JM. Epidemiology of osteoarthritis. Clin Geriatr Med. 2010;26(3):355-69. https://doi.org/10.1016/j.cger.2010.03.001

11. Vina ER, Kwoh CK. Epidemiology of osteoarthritis: literature update. Curr Opin Rheumatol. 2018;30(2):160. https://doi. org/10.1097/BOR.0000000000000479

12. Davatchi F, Sandoughi M, Moghimi N, Jamshidi AR, Tehrani Banihashemi A, Zakeri Z, et al. Epidemiology of rheumatic diseases in Iran from analysis of four COPCORD studies. Int J Rheum Dis. 2016;19(11):1056-62. https://doi.org/10.1111/1756-185X.12809

13. Newton JN, Briggs AD, Murray CJ, Dicker D, Foreman KJ, Wang H, et al. Changes in health in England, with analysis by English regions and areas of deprivation, 1990-2013: a systematic analysis for the Global Burden of Disease Study 2013. Lancet. 2015;386(10010):2257-74. https://doi.org/10.1016/S0140-6736(15)00195-6

14. Health at a glance 2015. OECD indicators, Paris: OECD Publishing; 2015. https://dx.doi.org/10.1787/health_glance-2015-en

15. Esfandiaribayat M, Ghavam A, Yazdanpanah A. Comparing the cost of joint replacement surgery in patients receiving social security insurance in Shahid Beheshti and Shahid Chamran hospitals in Shiraz. Biosci Biotech Res Comm. 2017;(Suppl 1):139-45.

16. Olyaeemanesh A, Behzadifar M, Mousavinejhad N, Behzadifar M, Heydarvand S, Azari S, et al. Iran's health system transformation plan: a SWOT analysis. Med J Islam Repub Iran. 2018;32:39. https://doi.org/10.14196/mjiri.32.39

17. Hochberg MC, Altman RD, April KT, Benkhalti M, Guyatt G, McGowan J, et al. American College of Rheumatology 2012 recommendations for the use of non-pharmacologic and pharmacologic therapies in osteoarthritis of the hand, hip, and knee. Arthritis Care Res. 2012;64(4):465-74. https://doi.org/10.1002/acr.21596

18. Ham C, Coulter A. Explicit and implicit rationing: taking responsibility and avoiding blame for health care choices. J Health Serv Res Policy. 2001;6(3):163-9. https://doi.org/10.1258/1355819011927422 
19. Bryant JH. Health priority dilemmas in developing countries. In: Coulter A, Ham C, editors. The global challenge of health care rationing. Philadelphia: Open University Press; 2000.

20. Dowsey MM, Gunn J, Choong P. Selecting those to refer for joint replacement: who will likely benefit and who will not? Best Pract Res Clin Rheumatol. 2014;28(1):157-71. https://doi.org/10.1016/j.berh.2014.01.005

21. Coombes R. Rationing of joint replacements raises fears of further cuts. BMJ. 2005;331(7528):1290. https://doi.org/10.1136/ bmj.331.7528.1290

22. Jain NB, Guller U, Pietrobon R, Bond TK, Higgins LD. Comorbidities increase complication rates in patients having arthroplasty. Clin Orthop Relat Res. 2005;435:232-8. https://doi.org/10.1097/01.blo.0000156479.97488.a2

23. Jiganti JJ, Goldstein WM, Williams CS. A comparison of the perioperative morbidity in total joint arthroplasty in the obese and nonobese patient. Clin Orthop Relat Res. 1993;(289):175-9.

24. Davis W, Porteous M. Joint replacement in the overweight patient: a logical approach or new form of rationing? Ann R Coll Surg Engl. 2007;89(3):203-6. https://doi.org/10.1308/003588407X183247

25. Lonner JH, Hershman S, Mont M, Lotke PA. Total knee arthroplasty in patients 40 years of age and younger with osteoarthritis. Clin Orthop Relat Res. 2000;380:85-90. https://doi.org/10.1097/00003086-200011000-00012

26. Fortin PR, Clarke AE, Joseph L, Liang MH, Tanzer M, Ferland D, et al. Outcomes of total hip and knee replacement: preoperative functional status predicts outcomes at six months after surgery. Arthritis Rheum. 1999;42(8):1722-8. https://doi.org/10.1002/15290131(199908)42:8<1722::AID-ANR22>3.0.CO;2-R

27. Brekke KR, Nuscheler R, Straume OR. Gatekeeping in health care. J Health Econ. 2007;26(1):149-70. https://doi.org/10.1016/j. jhealeco.2006.04.004

28. Tennant A, Fear J, Pickering A, Hillman M, Cutts A, Chamberlain M. Prevalence of knee problems in the population aged 55 years and over: identifying the need for knee arthroplasty. BMJ 1995;310(6990):1291-3. https://doi.org/10.1136/bmj.310.6990.1291

29. Fertig A, Roland M, King H, Moore T. Understanding variation in rates of referral among general practitioners: are inappropriate referrals important and would guidelines help to reduce rates?. BMJ. 1993;307(6917):1467-70. https://doi.org/10.1136/ bmj.307.6917.1467

30. Feld LP, Reulier E. Strategic tax competition in Switzerland: evidence from a panel of the Swiss cantons. Ger Econ Rev. 2009;10(1):91-114. https://doi.org/10.1111/j.1468-0475.2008.00443.X

31. Dakin H, Gray A, Fitzpatrick R, MacLennan G, Murray D. Rationing of total knee replacement: a cost-effectiveness analysis on a large trial data set. BMJ Open. 2012;2(1):e000332. https://doi.org/10.1136/bmjopen-2011-000332

32. Gwynne-Jones DP, Iosua EE, Stout KM. Rationing for total hip and knee arthroplasty using the New Zealand Orthopaedic Association score: effectiveness and comparison with patient-reported scores. J Arthroplasty. 2016;31(5):957-62. https://doi. org/10.1016/j.arth.2015.11.022

33. Hudak PL, Clark JP, Hawker GA, Coyte PC, Mahomed NN, Kreder HJ, et al. “You're perfect for the procedure! Why don't you want it?” Elderly arthritis patients' unwillingness to consider total joint arthroplasty surgery: a qualitative study. Med Decis Making. 2002;22(3):272-8. https://doi.org/10.1177/0272989X0202200315

34. Nourbakhsh M, Zarezadeh A, Shemshaki H, Etemadifar MR, Moezi M, Mazoochian F. Translation and cultural adaptation of the oxford hip score for Iranian population. Int J Prev Med. 2013;4(2):141-5.

35. Hawker GA, Wright JG, Coyte PC, Williams JI, Harvey B, Glazier R, et al. Determining the need for hip and knee arthroplasty: the role of clinical severity and patients' preferences. Med Care. 2001;39(3):206-16. https://doi.org/10.1097/00005650-20010300000002

36. Jüni P, Dieppe P, Donovan J, Peters T, Eachus J, Pearson N, et al. Population requirement for primary knee replacement surgery: a cross $\square$ sectional study. Rheumatology (Oxford). 2003;42(4):516-21. https://doi.org/10.1093/rheumatology/keg196

37. Kapiriri L, Martin DK. Priority setting in developing countries health care institutions: the case of a Ugandan hospital. BMC Health Serv Res. 2006;6(1):127. https://doi.org/10.1186/1472-6963-6-127

38. Woolhead G, Donovan J, Chard J, Dieppe P. Who should have priority for a knee joint replacement? Rheumatology. 2002;41(4):390-4. https://doi.org/10.1093/rheumatology/41.4.390

39. Aslani H, Nourbakhsh ST, Lahiji FA, Heydarian K, Jabalameli M, Ghazavi MT, et al. Iranian Joint Registry (Iranian National Hip and Knee Arthroplasty Registry). Arch Bone Jt Surg. 2016;4(2):192-6.

40. Winpenny EM, Miani C, Pitchforth E, King S, Roland M. Improving the effectiveness and efficiency of outpatient services: a scoping review of interventions at the primary-secondary care interface. J Health Serv Res Policy. 2017;22(1):53-64. https://doi. org/10.1177/1355819616648982 